\title{
PÓS-MODERNIDADE E PASTICHE EM “A CASA QUE JACK CONSTRUIU”
}

\author{
Gabriela Sá Pauka.
}

RESUMO: O presente artigo tem como objetivo a investigação do modelo de produção artística da pós-modernidade - interartística, auto reflexiva e fragmentada. Para tanto, o filme A casa que Jack Construiu (2018), de Lars von Trier, será utilizado. O filme de Trier apresenta os relatos de um serial killer cujas pretensões artísticas se delineiam como espécie de ensaio sobre as relações entre a performance estética e o mal, radicando no solo árido da contemporaneidade ecos corrompidos das antigas ambições do gênio romântico. Pretende-se, para tal, investigar o modo pelo qual o filme opera, de maneira consciente, o pastiche da estética do sublime, a partir da apropriação das referências da alta cultura artística e literária, evocada por meio de um processo de bricolagem, em que a distorção se imprime como atestado da angústia criativa na contemporaneidade.

Palavras-Chave: A Casa que Jack Construiu. Sublime. Pós-modernidade. Pastiche.

ABSTRACT: This article aims to investigate the postmodern artistic production model, which is identified as interartistic, self-reflective and fragmented. Therefore, the film The House Jack Built (2018), by Lars von Trier, will be used. Trier's film presents the reports of a serial killer, with artistic pretensions, which are outlined as a kind of essay on the relations between aesthetic performance and evil, rooted in the arid soil of the contemporary corrupted echoes of the old ambitions of the romantic genius. To this end,

\footnotetext{
${ }^{\text {I }}$ Mestranda na Universidade Estadual Paulista "Júlio Mesquista Filho", UNESP, Faculdade de Ciências e Letras, Câmpus Assis. Possui graduação em Letras - Inglês, Português e suas Respectivas Literaturas pela Universidade de Rio Verde. Tem experiência na área de Literatura e Língua Inglesa. E-mail: gabrielasapauka@gmail.com
} 
we intend to investigate the way in which the film consciously operates the pastiche of the aesthetics of the sublime, from the appropriation of the references of high artistic and literary culture, evoked through a bricolage process, in which the distortion is printed as a testament to the creative anguish in contemporary times.

Keywords: The House that Jack Built. Sublime. Postmodernity. Pastiche.

\section{INTRODUÇÃO}

Este estudo pretende investigar a maneira pela qual o esforço performático da realização artística se dá na contemporaneidade, momento histórico marcado pela insuficiência, já que, nessa época, segundo Jameson, “[...] o número de combinações possíveis é restrito; os estilos mais singulares já foram concebidos" (JAMESON, i99ı, p. 19). Usaremos, para tanto, A Casa que Jack Construiu (2018), de Lars von Trier, como objeto de estudo analítico descritivo na investigação das peculiares sendas criativas da contemporaneidade.

No último filme de Trier, a personagem Jack aspira a excelência artística marcada pela linguagem do sublime. Entretanto, a obra de Jack está aquém da grandeza pretendida, enfrentando limitações que traduzem condições típicas do sujeito contemporâneo, que no filme se manifestam numa linguagem artística que se vale do pastiche (JAMESON, I99I) e eventualmente se aproxima crítica e conscientemente do kitsch (GREENBERG, 20II). Tais elementos expressam a impossibilidade do protagonista de realizar uma performance verdadeiramente grandiosa. O filme é marcado por uma profusão de referências à alta literatura e às artes plásticas - Blake, Delacroix, Virgílio - e, desse modo, faz convite ao debate acerca da influência excruciante que perpassa o sujeito artístico contemporâneo (BLOOM, I99I).

Tenciona-se, a partir destas considerações, averiguar como o pastiche, processo de produção cultural que propõe solução para a questão da impossibilidade da criação na pós-modernidade, acontece neste filme. Logo, realizar-se-á a elencagem de algumas das referências poéticas e plásticas nele presentes a fim de se estabelecer a maneira pela qual o pastiche e a estética do sublime se entrelaçam e, consequentemente, os caminhos pelos 
quais o filme se relaciona com a alta literatura. A elencagem das alusões à alta literatura e às artes plásticas resume a hipótese deste trabalho: de que na criação artística contemporânea o pastiche se oferece como componente expressivo e o kitsch, definido por Greenberg (2011, p. 29) como "simulacros aviltados da cultura genuína", surge como uma constante ameaça da qual, eventualmente, a arte se aproxima de modo crítico e autoconsciente.

O trabalho com conceitos como pós-modernidade e estéticas que lhe sejam possíveis garante a pertinência do estudo, pois, segundo Umberto Eco, a investigação de objetos de análise contemporâneos são os mais desafiadores, já que carecem de bases canônicas para encaminhar a pesquisa e afastam pesquisadores (ECO, 20or, p. 33). Dessa forma, concentrar a atenção nas reverberações da alta literatura para a criação da linguagem hodierna do sublime é contribuir para a construção de caminhos de estudo. Apesar do montante módico de trabalhos sobre a pós-modernidade (ECO, 200I, p. 35), alguns autores contribuíram consideravelmente com a área de estudos contemporâneos. Serão usados aqui publicações de teóricos como Clement Greenberg, Harold Bloom, Fredric Jameson e Linda Hutcheon.

\section{Pós-Modernidade}

A atualidade tem sido compreendida e, portanto, denominada de diversas maneiras. Entretanto, o conceito para o contexto hodierno utilizado neste trabalho será aquele dado por Fredric Jameson (1985). Logo, o momento presente será aqui referenciado e entendido como pós-modernidade, já que as características do fenômeno definido pelo estudioso - a saber a produção cultural posterior pós-guerra, marcada por autoconsciência e fragmentação - dialogam diretamente com a linguagem estética do objeto desta investigação, A Casa que Jack Construiu. Segundo o crítico literário, as profundas transformações ocorridas a partir da metade do século XX determinaram uma condição de práticas culturais específicas, validando a designação. A noção de pós-modernidade abarca, portanto, a periodização da “[...] nova fase do capitalismo a partir do crescimento econômico do pós-guerra nos Estados Unidos, no final dos anos 40 e começo dos 50 [...]” (JAMESON, 1985, p. 18). 
A pós-modernidade diz respeito, portanto, a uma nova totalidade social, com princípios organizadores próprios, tais como mudanças nos modos de produção, consumo e circulação de bens simbólicos assim como nas práticas e experiências cotidianas de grupos que estariam desenvolvendo novas estruturas de identidade. A compilação de códigos e de linguagens híbridas dão ao universo pós-moderno papel sine qua non à imagem, à revisão da tradição e à fragmentação.

Ainda segundo Jameson, o sujeito pós-moderno experimenta certa relação esquizofrênica com o tempo, ou seja, é incapaz de organizar o passado e o presente como experiências correntes $e$, por isso, revisita a tradição cultural reiteradamente. $O$ esmaecimento da historicidade torna-se, portanto, elemento que determina o nítido caráter fragmentado e híbrido das produções culturais pós-modernas.

Por conseguinte, a relação com obras modernas ganha novos parâmetros. Por exemplo, "Joyce e Picasso não somente deixaram de ser esquisitos e repulsivos como se tornaram clássicos e adquiriram agora para nós uma aparência de realistas” (JAMESON, I985, p. 25). Em outras palavras,

\begin{abstract}
Os clássicos da modernidade anterior são agora parte do assim chamado cânon, e são ensinados em escolas e universidades - o que, por sua vez, os esvazia de todo seu velho potencial subversivo. De fato, um modo de marcar a ruptura entre os períodos e datar o surgimento da pós-modernidade pode se encontrar precisamente aí: na época (parece que início dos anos 6o) em que a posição do modernismo radical e sua estética dominante se institucionalizaram na Universidade, quando passaram a ser considerados acadêmicos por toda uma geração de poetas, pintores e músicos. (JAMESON, 1985, p. 26)
\end{abstract}

Consequência disso é o surgimento do pastiche, "[...] um modo de chegar a acordo com os textos desse "rico e temível legado do passado" (HUTCHEON, 1985, p. 15).

\title{
3 O pastiche e o kitsch
}

O pastiche é "[...] como a paródia, a imitação de um estilo singular ou exclusivo, a utilização de uma máscara estilística, uma fala em língua morta [...]” (JAMESON, 1985, p. 18). Entretanto, sua prática é neutra: não tem ímpeto cômico ou o impulso crítico da paródia. A obra elaborada em linguagem de pastiche pode imitar servilmente um texto canônico ou então fundir trechos vários de inúmeras obras. 
O surgimento do pastiche está intimamente ligado à massificação cultural, responsável por transformar bens artísticos em mercadorias produzidas "industrialmente em série" (ECO, 2006, p. 27). A reprodução técnica desses bens culturais provoca a dessacralização da aura da obra de arte (BENJAMIM, 1985, p. I68), alterando a maneira pela qual esta passa a ser produzida e fruída.

Além disso, a “[...] razão pela qual os artistas e os escritores do presente não conseguirão mais inventar novos estilos e mundos - é que todos estes já foram inventados; o número de combinações possíveis é restrito; os estilos mais singulares já foram concebidos" (JAMESON, I991, p. 19). Ou seja, as grandes inovações estéticas foram esgotadas durante o Modernismo. Resta, agora, ao sujeito pós-moderno costurar referências e estilos já consagrados na tentativa de elaboração de uma grande obra. Trabalha-se, portanto, baseando-se em um formato de produção autorreflexiva e interartística - um novo modelo para processos artísticos, uma abordagem criativa da tradição (HUTCHEON, 1985, p. ı6).

O kitsch, em contrapartida, demonstra de modo mais ostensivo os impasses da produção artística hodierna que aspira ao genuíno. Greenberg conceitua kitsch como “[...] simulacros aviltados da cultura genuína" (20II, p. 29); ou ainda, uma "experiência por procuração e sensações falsificadas" (GREENBERG, 2oII, p. 32). Ou seja, o kitsch simula o contato artístico, de modo que o público acredite que esteja fruindo genuinamente uma obra, enquanto, na verdade, a arte que lhe é entregue está previamente digerida, desprovida de reflexão. Desse modo, o kitsch imita os efeitos e elimina o caráter subversivo da arte, favorecendo a manutenção do status quo. "É produto da revolução industrial, urbanização e alfabetização universal” (GREENBERG, 20II). O kitsch, porque serve à produção massificada é forçado a mostrar lucros. Está, portanto, a serviço da necessidade do trabalhador em consumir imagens em seu curto tempo de lazer, e não de um desejo de expansão da própria subjetividade. O kitsch não vê fronteiras culturais e geográficas, elimina o espaço dos métodos artesanais e, consequentemente, a identidade singular de cada grupo social, massificando-nos.

Greenberg aponta como pré-condição para o kitsch uma tradição cultural plenamente amadurecida e consciente de si mesma, uma sociedade produto do 
esgotamento das vanguardas modernistas. E somente casos acidentais e isolados são eventos de verdadeiro valor artístico. Para Greenberg, os caminhos para a produção contemporânea continuarão sombrios enquanto as configurações da sociedade pósmoderna, a saber pós-industrial de capitalismo multinacional, existam.

\section{${ }_{4} \mathrm{O}$ sublime}

De acordo com Edmund Burke, o sublime "produz a mais forte emoção que o espírito humano é capaz” (BURKE, I993, p. 48). Em Investigações, o estudioso relaciona o sublime com tudo aquilo que desperta medo, terror e privação. Além disso, tudo aquilo que poderá dilacerar a subjetividade humana cuja base reside em parâmetros de tempo e espaço. Em outras palavras, "uma relação de ameaça diante da grandeza do que quer que seja, pois nela pressentimos uma potência capaz de nos destruir" (FIGUEIREDO, 2oII, p. 40). Portanto, as grandes obras de arte seriam aquelas que nos causariam angústia proveniente da ameaça de morte.

O sublime está intimamente ligado à noção de deleite, definida por Burke como “sensação da eliminação da dor ou do perigo" (BURKE, 1993, p. 45). Desse modo, tudo aquilo de terrível que possa agitar o espírito humano deve fazê-lo a certa distância, distância segura e somente possível na apreciação da obra de arte. Nossa capacidade de resistência, a apreensão de nossa pequenez frente a mares revoltos, grandes alturas, tempestades violentas - espetáculo de uma natureza desregrada - é fonte para o deleite desde que nos encontremos em segurança. E, assim como um sonho, a experiência de uma peça de teatro ocorre ligada ao sofrimento da imersão na experiência e posterior alívio da desconexão. Sofrimento e prazer caminham de maneira concomitante no sublime, realizável apenas no distanciamento da fruição da obra de arte.

\section{A Casa que Jack Construiu}

Em A Casa que Jack Construiu (2018), filme do polêmico cineasta Lars Von Trier, Jack, interpretado por Matt Dillon, é personagem principal. O engenheiro civil de 
aspirações artísticas comete assassinatos diversos e narra a um homem misterioso identificado como Virgílio, cinco de seus homicídios praticados.

O diálogo acontece durante uma descida dantesca através dos círculos infernais, enquanto Jack compara seus crimes a obras de arte por duas razões: primeiramente porque os homicídios são produtos de tormentos psíquicos e indagações existenciais de Jack e, em segundo lugar, porque buscam certa transcendência. Ou seja, Jack acredita que seus crimes sejam performances artísticas da mais alta ordem, já que instigam, perscrutam, investigam e buscam a transcendência tanto quanto qualquer outra forma de arte (BOSCOV, 2020).

O discurso de Jack também perora sobre assuntos como gênio artístico, o poder icônico de certas criações nazistas, violência como a última instância a conferir subversão à arte e finalmente sobre a relevância das matérias-primas para o produto artístico final. Suas preleções vêm intercaladas por filmetes do pianista Glenn Gould, imagens do arquiteto Albert Speer em reunião com Adolf Hitler, obras-primas da pintura e poemas de William Blake.

No decurso de sua narrativa, Jack trabalha com os corpos congelados de suas vítimas na produção de fotografias e esculturas. Entrementes, projeta, constrói e demole repetidas vezes sua futura casa. A reflexão exigida para cada um de seus "trabalhos" é laboriosa: o engenheiro experimenta diferentes materiais, pessoas e procedimentos, obtendo insólitos resultados com os cadáveres e pouco progresso com a alvenaria. Ao longo desse processo, Jack discorre sobre a importância do material usado em cada empreitada. A palavra “respeito" às vontades do material utilizado aparece diversas vezes. O longa-

metragem culmina com Jack edificando uma pequena casa com os corpos ao seu dispor, lugar onde se localiza a abertura para sua caminhada infernal.

\section{$6 O$ pastiche do sublime}

O pastiche, como dito anteriormente, é emulação de estilos canônicos, ou seja, é espécie de bricolagem de referências da alta cultura realizada pelo artista contemporâneo 
como forma de lidar com o temível peso da tradição em um momento que a originalidade não é mais possível.

A Casa que Jack Construiu, na condição de filme pós-moderno, não é exceção à regra. A narrativa da última obra de Trier faz uso da linguagem do pastiche em diversos momentos. E o faz de maneira consciente de seu caráter de reaproveitamento da cultura, elevando-se como um pastiche crítico, consciente, autorreferente. Elencaremos e analisaremos alguns deles:

Primeiramente, o pastiche é encontrado na própria base do enredo. Da mesma forma que Dante, em Inferno (DANTE, 2013), é guiado por Virgílio através do rio Aquaronte e posteriormente pelos nove círculos do inferno, também o é Jack. E da mesma maneira que Dante pondera questões intrínsecas ao seu contemporâneo, Jack assim o faz. Além disso, há clara alusão à obra de Eugène Delacroix, A Barca de Dante (DELACROIX, 1822). Trier visita e reelabora a primeira parte da Divina Comédia, assim como a atualiza aos seus personagens a tela do pintor francês. A seguir, ambas imagens:

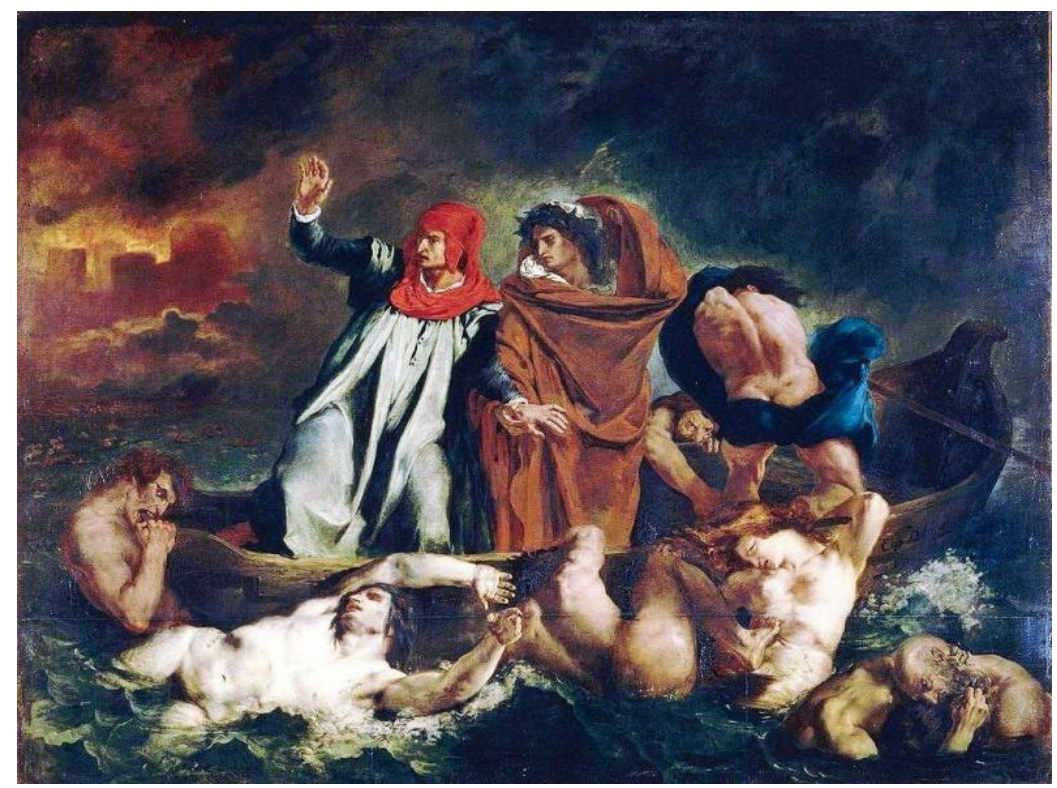

Figura i: DELACROIX, I822. A barca de Dante. Óleo sobre lona, I89 x 24I. Museu do Louvre, Paris 


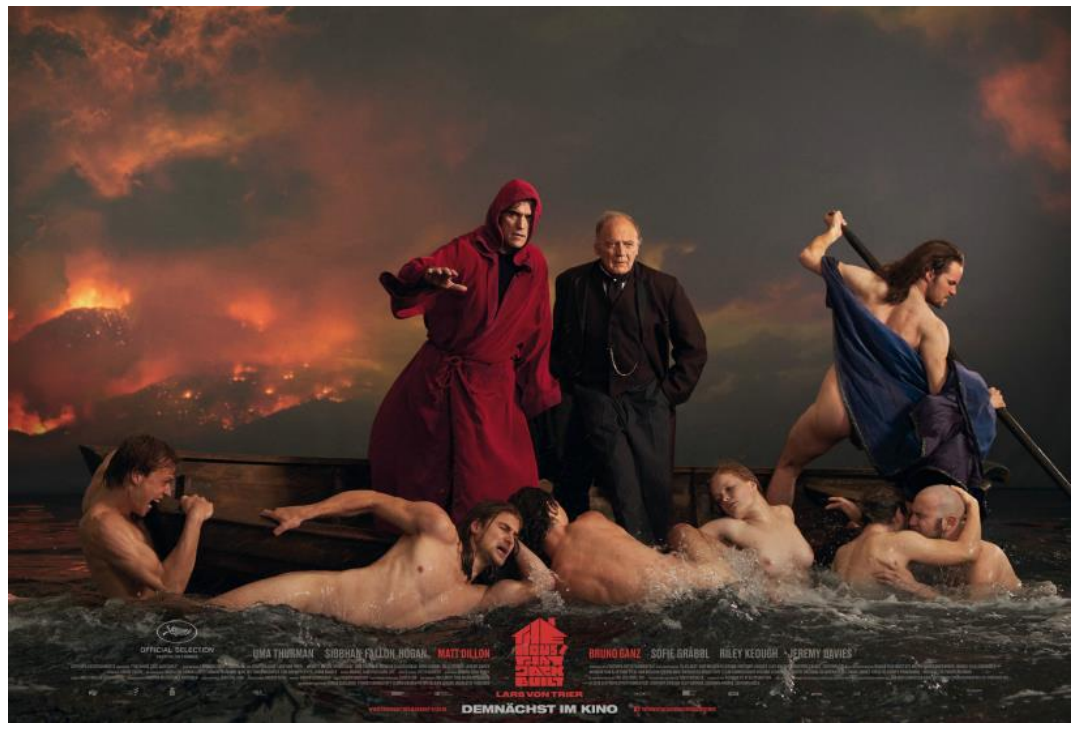

Figura 2: VON TRIER, A casa que Jack construiu. Califórnia Filmes, 2018

Ademais, a pintura de Delacroix e o poema épico de Dante conferem ao último filme de Trier certo grau de sublime, já que a importância de ambas obras na construção da identidade cultural ocidental é gigantesca. Além disso, há uma reconstrução irônica do quadro de Delacroix. Na obra plástica, temos Dante com as vestes escarlates com que ele é tradicionalmente representado, já no filme temos Jack vestido com a capa que ele utilizava para tratar com os cadáveres de suas vítimas. Em Delacroix, temos Virgílio representado com a dignidade da toga romana, em Trier Virgílio surge como vestido com a elegância sóbria de um cavalheiro de fins do século XIX e início do século XX. Ademais, os corpos dos condenados reproduzem exatamente as posições dos corpos da pintura de Delacroix. Isso tem consequências, pois há dois planos que se sobrepõem, em que personagens contemporâneos são lançados no universo fantástico da tela.

Ainda sobre a proposta cinematográfica, deve-se mencionar o contexto em que essa imagem aparece no filme: num momento de suspensão da ação, de paralisia da cena na contenção pictórica. A cena não é totalmente estática, mas desacelerada. Trier utiliza esse recurso em outros filmes, lembro-me da imagem do cavalo rampante (ou caindo, lembrome vagamente) no filme melancolia. Essas questões de arquitetura da narrativa da obra poderiam ser contempladas com grande benefício para suas análises. 
Outro ponto de importância para a elaboração do filme na perspectiva de produção artística pós-moderna é a apropriação crítica e irônica da estética kitsch. Essa “prática específica do pastiche não é culta, mas existe no próprio interior da cultura de massa e é genericamente conhecida como o filme de nostalgia" (JAMESON, I99I, p. 20). Elemento primordial para sua conceituação é a procura pelo resgate de certas singularidades estilísticas de certo momento histórico. É importante que o período referenciado desperte a sensação de nostalgia a fim de ou satisfazer um profundo anseio de revivê-lo ou de se relacionar de forma ingênua, pouco crítica e idealizada com o tempo. É, dessa forma,

[...] extremamente sintomático constatar que o estilo dos filmes de nostalgia esteja invadindo e colonizando até mesmo os filmes atuais que têm cenários contemporâneos: como se, por alguma razão, fôssemos hoje incapazes de focalizar nosso próprio presente, como se tivéssemos nos tornado inaptos para elaborar representações estéticas de nossa própria experiência corrente" (JAMESON, 199I, p. 2I).

Percebe-se que a década referenciada por A Casa que Jack Construiu é a de 6o. Primeiramente, pelo figurino correspondente - óculos de armações grandes, calças boca de sino, cabelos repicados, etc. - e também através do design de carros e edifícios. Trier escolhe deliberadamente detalhes que fazem alusão a uma das décadas de maior profusão cultural e, consequentemente, repleta de elementos saudosistas. O que acontece, portanto, na pós-modernidade e exemplificado aqui por é “[...] uma versão muito mais limitada e controlada desta ativação do passado, dando-lhe um contexto novo e, muitas vezes, irônico, faz exigências semelhantes ao leitor mas trata-se mais de exigências aos seus conhecimentos e à sua memória [...]” (HUTCHEON, I985, p. 16).

E, além disso, há clara referência ao clipe Subterranean Homesick Blues (DYLAN, 1965), de Bob Dylan, produzido em 1965. A narrativa do filme é dividida em capítulos: há cinco incidentes numerados de modo ordinal, um prelúdio e um prólogo. Cada um desses capítulos é iniciado por uma cena que se repete: da mesma forma que Dylan faz em seu vídeo, Jack está em um beco, segurando placas de papel escritas de mesma fonte artesanal, deixando-as cair no chão conforme seu discurso progride, modulando a estrutura de um romance. 
Ademais, o filme abusa dos efeitos de distanciamento, teorizados por Bertolt Brecht, dramaturgo alemão ativo nos anos 20, e, 30 e 40. Como se sabe, o teórico tem grande ressonância sobre o trabalho de Trier: Dogville (TRIER, 2003) é uma peça brechtiana, assim como Dançando no escuro (TRIER, 200o). O Efeito de Distanciamento (Verfremdungseffekt, como o chama Brecht) é uma técnica dramática segundo o qual o uso ostensivo de artifícios (letreiros, canções, andaimes à mostra; personagens que se dirigem à plateia; cenários pintados a giz, etc.) quebram as expectativas de naturalismo do espetáculo, de modo a incomodar o público e leva-los à crítica consciente das situações encenadas. $\mathrm{O}$ efeito de distanciamento é uma forma de metalinguagem e ironia apropriada à quebra da ilusão da realidade e ao exercício da crítica.

Assim como fez com Delacroix, Trier incorpora e inverte conteúdo e estrutura do universo musical. Através de uma abordagem criativa, seu filme torna-se exemplo dos processos pós-modernos de produção artística em que os modelos serão híbridos e fragmentados. A arte pós-moderna beberá, portanto, da música, da pintura, da literatura, da escultura, da fotografia e outros lugares mais para a realização de uma peça cinematográfica polissêmica; e contribuirá para “[...] uma estética do processo, da atividade dinâmica da percepção, interpretação e produção de obras de arte" (HUTCHEON, 1985, p.12).

Essa estratégia abraçará outro grande nome na produção do filme, William Blake. Citado direta e indiretamente, dois de seus poemas servem como parâmetro de conduta para Jack. São eles O Cordeiro e O Tigre (BLAKE, 2005). A temática comum a Blake é conveniente a Jack e está concatenada numa postura de rejeição à oposição hierárquica entre o bem e o mal (DOS SANTOS, 2005, p. 47). O mal, segundo Blake, plasmado no poema $O$ Tigre, significa energia criativa; no sentido de que a arte verdadeira desmoraliza preceitos, deve ser transgressora para tirar daí sua subversão. Entretanto, em Blake, não há apologia ao mal per se - atributo que escapa a Jack. A morte, argumenta a personagem, funciona na atualidade como matéria e motor para a produção artística. $O$ sentido sublime no discurso de Jack é feito a partir da distorção das ideias de Blake. Aquele deseja a performance de um grande gesto criativo, e deturpa de Blake sua temática e 
credibilidade. A clara a distorção se imprime como atestado da angústia criativa na contemporaneidade.

As xilogravuras de William Blake aparecem em profusão, assim como telas futuristas, fauvistas, renascentistas. Em clara necessidade de diálogo com a tradição ocidental, o pastiche do sublime está também exemplificado nesse ponto. $\mathrm{Na}$ comparação entre seus bizarros negativos e relevantes pinturas de Blake, a linguagem do sublime lhe escapa e o resultado é grotesco. $\mathrm{Na}$ explanação sobre a sublimidade da arquitetura de igrejas góticas e a pretendida aura sublime de sua casa de corpos putrefatos, Jack produz objetos vulgares. $\mathrm{Na}$ exaltação da produção alemã nazista e da italiana fascista, ele é incapaz de alcançar o patamar que deseja - seja aquele que tangencia a sublimidade, seja aquele que se pretende relevante tal qual Dante.

\section{Considerações finais}

O presente artigo analisou, sob a ótica do modelo de produção artística da pósmodernidade, o filme A casa que Jack Construiu (2018), de Lars von Trier. Tencionou-se, investigar o modo pelo qual o filme opera, de maneira consciente, o pastiche da estética do sublime, a partir da apropriação das referências da alta cultura artística e literária, evocadas por meio de um processo de bricolagem, em que a distorção se imprime como atestado da angústia criativa na contemporaneidade.

Primeiramente, conceituou-se noções importantes como o sublime, a pósmodernidade e o pastiche. Então, guiado por teóricos como Linda Hutcheon, Fedric Jameson e Clement Greenberg alguns pontos da obra cinematográfica foram examinados. Foram eles: referências à alta literatura, como Inferno, de Dante; poemas e xilogravuras de William Blake; a estética kitsch na elaboração gráfica; e a linguagem do pastiche na contemporaneidade.

Concluiu-se que, como produto artístico pós-moderno, A casa que Jack Construiu (TRIER, 2018) compila diferentes aspectos dos modelos de produção artística da atualidade. $\mathrm{O}$ mais recente filme do diretor dinamarquês é híbrido, fragmentado, auto reflexivo e espelha a impossibilidade de um grande gesto criativo contemporâneo. $O$ 
sublime aqui é pretendido - e somente possível - através da linguagem do pastiche; porém, devido às singularidades da personagem, temos o delírio resultante do peso esmagador da tradição.

\section{REFERÊNCIAS}

BENJAMIN, Walter. Magia e técnica, arte e política. São Paulo: Brasiliense, 1985.

BLAKE, William. Canções da Inocência e da Experiência. Tradução, prefácio e notas de Mário Alves e Leonardo Gonçalves. Belo Horizente: Crisálida, 2005.

BLOOM, Harold. A angústia da influência: uma teoria da poesia. Tradução de Miguel Támen. Lisboa: Edições Cotovia, 199ı.

BOSCOV, Isabela. "A Casa que Jack Construiu": a mente estranha de Lars von Trier. Revista Veja. Disponível em: https://veja.abril.com.br/blog/isabela-boscov/a-casa-quejack-construiu/. Acesso em: 20/or/2020.

BURKE, E. Uma investigação filosófica sobre a origem de nossas idéias do sublime e do belo. Tradução de Enid Abreu Dobránszky. Campinas: Papirus, 1993.

DOS SANTOS, Alcides Cardoso. O Mal como Gênio Poético nas Ilustrações do Livro de Jó, de William Blake. Terra Roxa e Outras Terras: Revista de Estudos Literários, volume 6, p. 44-63, 2005 .

DANTE, Alighieri. Inferno. London: Penguin Classics, 2013.

ECO, Umberto. Como se faz uma tese. Perspectiva, 2009.

DANÇANDO no Escuro (Dancer in the Dark). Direção: Lars Von Trier. Intérpretes: Björk, Catherine Deneuve, David Morse, Peter Stormare, Cara Seymour, Vladica Kostic e Jean-Marc Barr. Música: Björk e Vincent Mendoza. 20oo. DVD (I40 min), widescreen, color. Produção: Zentropa Entertainments.

Trier, Lars Von (2003) Dogville, Denmark.

FIGUEIREDO, Virginia. O sublime explicado às crianças. Trans/Form/Ação, v. 34, n. SPE2, p. 35-56, 20II.

GREENBERG, Clement et al. Clement Greenberg e o debate crítico. Rio de Janeiro: Jorge Zahar, 200I. 
HUTCHEON, Linda. Uma teoria da paródia. Tradução de Teresa Louro Pérez. Lisboa: Edições 70, 1985 .

JAMESON, Fredric. Postmodernism, or the cultural logic of late capitalism. Duke University Press, I991.

LONGINO. Do Sublime. Tradução de Filomena Hirata. São Paulo: Martins Fontes, 1996.

VON TRIER, Lars. A casa que Jack construiu. Califórnia Filmes, 2018. 